\title{
LV-OP-2-7
}

\section{Risk factors for poor survival after recurrence of hepatocellular carcinoma after liver transplantation}

\author{
Jinsoo RHU, Jae-Won JOH*, Gyu-Seong CHOI, Jong Man KIM \\ Department of Surgery, Samsung Medical Center, Seoul, Korea
}

Introduction: This study was designed to analyze the risk factors for poor survival after recurrence of hepatocellular carcinoma after liver transplantation.

Methods: Patients who underwent liver transplantation for hepatocellular carcinoma during the period of 2007 to 2018 were reviewed and patients who experienced recurrence were included. Multivariable Cox proportional hazard ratio were performed for potential risk factors for survival after recurrence. Pre-transplantation characteristics as well as variables related to the recurrence and treatment for recurrence were included for the analysis.

Results: A total of 151 liver transplantation recipients experienced hepatocellular carcinoma recurrence after liver transplantation. Median duration of recurrence-free period was 9.3 months (0.89 to 97.25 months). Median follow up duration after recurrence was 13.4 months (0.59 to 118.28 months). One-, 3 -, and 5-year survival after recurrence were $65.2 \%, 34.0 \%$ and $20.5 \%$, respectively. Multivariable Cox analysis showed that, graft from living donor ( $\mathrm{HR}=0.364, \mathrm{CI}=0.177-0.748, p=0.006)$, recurrence-free interval $\geq 9$ months ( $\mathrm{HR}=0.273, \mathrm{CI}=0.174-0.428, p<0.001)$, alpha-fetoprotein $\geq 100 \mathrm{ng} / \mathrm{mL}$ at the time of recurrence $(\mathrm{HR}=1.816, \mathrm{CI}=1.158$ $2.848, p=0.009)$, and bone metastasis $(\mathrm{HR}=2.031, \mathrm{CI}=1.237-3.334, p=0.005)$ were related to survival after recurrence. In patients with solitary metastasis of single organ, recurrence-free interval $\geq 9$ months $(\mathrm{HR}=0.212, \mathrm{CI}=0.091-0.493, p<0.001)$, multiple tumor in the extracted liver $(\mathrm{HR}=3.409, \mathrm{CI}=1.457-7.974, p=0.005)$, and lymph node metastasis $(\mathrm{HR}=4.688, \mathrm{CI}=1.671-13.156, p=0.003)$ were related to survival after recurrence.

Conclusions: Although the survival was generally poor after recurrence of hepatocellular carcinoma in liver transplantation recipients, prolonged survival can be achieved in certain patients with better prognostic factors. Therefore, appropriate treatment should be performed even with transplantation recipients with hepatocellular carcinoma recurrence. 